\title{
LIQUID JUNCTION PHOTOCELLS SYNTHESIZED WITH DYE COATED ZINC OXIDE FILMS
}

\section{P. SAMARASEKARA}

\section{Department of Physics, University of Peradeniya, Peradeniya, Sri Lanka}

Email: pubudus@phy.ruh.ac.lk

\begin{abstract}
Zinc oxide $(\mathrm{ZnO})$ films fabricated using low cost methods were employed to synthesize a liquid junction photocell explained in this report. Methyl violet dye has been coated on $\mathrm{ZnO}$ films to enhance the light absorption. The thickness of the $\mathrm{ZnO}$ film and the separation between the Platinum electrode and $\mathrm{ZnO}$ film were varied in order to obtain the maximum efficiency of the photocell. The best photocurrent and photo-voltage could be measured for $\mathrm{ZnO}$ films coated with methyl violet dye for 12 hours. The optimum photocurrent obtained was $0.24 \mathrm{~mA} / \mathrm{cm}^{2}$, which was a higher photocurrent for Methyl violet coated $\mathrm{ZnO}$ films. But the photo-voltage measured was comparable to the photovoltage of $\mathrm{ZnO}$ films measured by some other researchers. Hence, a considerably higher optimum efficiency such as $2.4 \%$ could be obtained for these $\mathrm{ZnO}$ films consist of $\mathrm{ZnO}$ nanoparticles. The higher effective surface area provided by $\mathrm{ZnO}$ nanoparticles is the possible reason for this higher photocurrent.
\end{abstract}

Keywords: Zinc Oxide, I-V characteristic curves, photocell, photocurrent and photovoltage

\section{INTRODUCTION}

Because zinc oxide $(\mathrm{ZnO})$ is electrically conductive and visually transparent, $\mathrm{ZnO}$ thin films are extensively used in photo-voltaic applications, electric transducers, nanowires, integrated optics including optical wave guides, displays and heaters. Materials with wide band gaps such as $\mathrm{ZnO}$ can be used in solar cells to absorb the UV part of the solar spectrum. $\mathrm{ZnO}$ thin films have been previously synthesized by rf magnetron sputtering on glass substrates (Jeong et al., 2004) and by pulsed laser ablation on sapphire substrates (Cao et al., 1998). ZnO:Al thin films have been grown by off-axis rf magnetron 


\section{P Samarasekara}

sputtering on amorphous silica substrates (Jayaraj et al., 2002). ZnO nanowires have been deposited by the thermal evaporation /condensation method (Jo et al., 2003). For solar energy applications, chemical vapor deposition (Maruyama, 1993), the quasi-closed space vacuum sublimation technique (Bobrenko et al., 1994) and the screen printing technique (Knodler et al., 1993) have been also employed to grow thin films of $\mathrm{ZnO}$.

Earlier thin films of $\mathrm{ZnO}$ have been sputtered by us (Samarasekara et al., 2002). The photo-voltage of these $\mathrm{ZnO}$ thin films sputtered using DC reactive sputtering varied with the sputtering conditions such as sputtering pressure, sputtering time period and substrate temperature. Nevertheless, the photo-current of these sputtered $\mathrm{ZnO}$ thin films were found to be really small because of the high band gap of $\mathrm{ZnO}$. In this paper, the photocurrent variation of methyl violet dye coated $\mathrm{ZnO}$ films prepared using a low cost method are discussed.

\section{EXPERIMENTAL}

High purity $\mathrm{ZnO}$ nanoparticles produced by American Elements Company were ground well to make a uniform sample of fine nanoparticles. The original size of these nanoparticles was about $50 \mathrm{~nm}$. These nanoparticles were mixed with ethyl alcohol to prepare a paste. A layer of this paste was uniformly applied on the conductive surface of conductive glass plates which were cleaned in an ultrasonic cleaner. The alcohol of this sample evaporated within one hour by leaving a layer of $\mathrm{ZnO}$ on conductive glass. Then the $\mathrm{ZnO}$ film sample was annealed in air in an oven at $450{ }^{\circ} \mathrm{C}$ for 30 minutes to crystallize the $\mathrm{ZnO}$ phase and to make the film adhesive to conductive glass substrate. After the sample cooled down in oven, it was taken out for dye treatment and measurements. Samples with area of $1 \mathrm{~cm} \times 1 \mathrm{~cm}$ were prepared for the measurements. But the thicknesses of the samples were varied from $0.2 \mathrm{~mm}$ to $2 \mathrm{~mm}$ in order to investigate the effect of thickness on photocurrent. The samples were then immersed in methyl violet dye solutions and left in dye for 4-24 hours.

The photocell was prepared using this dye coated $\mathrm{ZnO}$ film sample and a platinum electrode. A platinum plate with same area as $\mathrm{ZnO}$ film sample was used as the counter electrode. The separation between platinum plate and $\mathrm{ZnO}$ film of this photocell was varied in the range of $0.4-1.4 \mathrm{~mm}$ in order to obtain optimum efficiency. Thereafter, the well sealed photocell was filled with $\mathrm{KI} / \mathrm{I}_{2}$ solution. $\mathrm{KI} / \mathrm{I}_{2}$ solution with $0.01 \mathrm{M} / 0.0001 \mathrm{M}$ concentration dissolved in distilled water and redox couple $\mathrm{I}_{3}{ }^{-} / \mathrm{I}^{-}$was used as the electrolyte in this liquid junction photocell, as the maximum efficiency could be obtained at this concentration. The variation of photocurrent with applied voltage was measured by means of computerized Keithly 236 source measurement unit, and a lamp calibrated similar to 
solar spectrum was employed to illuminate the photocell from the side of conducting glass. $\mathrm{X}$-ray diffraction (XRD) was performed to investigate the structure of $\mathrm{ZnO}$ samples.

\section{RESULTS AND DISCUSSION}

The I-V characteristic curves of $\mathrm{ZnO}$ film sample coated with methyl violet dye for 12 hours are shown in Figure 1. The area of all the samples described in this paper is 1 $\mathrm{cm}^{2}$. The photocurrent (or photo-voltage) has been defined as the difference between light and dark currents (or voltages). The minus signs of photocurrent and photo-voltage were disregarded. The photocurrent at $\mathrm{V}=0$ is $0.24 \mathrm{~mA} / \mathrm{cm}^{2}$, and the photo-voltage at $\mathrm{I}=0$ is $\mathrm{V}=$ $0.22 \mathrm{~V}$. Here dashed and solid lines indicate the dark and light I-V curves, respectively. The efficiency corresponding to this photocurrent and photo-voltage is $2.4 \%$. The photocurrent and photo-voltage vary with dye coating time, and they reach maximum values at dye coating time of 12 hours. Also the maximum photo-voltage and photocurrent could be obtained for film thickness of $0.6 \mathrm{~mm}$. Therefore, all the $\mathrm{ZnO}$ film samples explained in this paper are $0.6 \mathrm{~mm}$ thick. The separation between the $\mathrm{ZnO}$ film sample and the platinum electrode of photocell is $0.8 \mathrm{~mm}$ in this case. The photocurrent and the photovoltage were optimum, when the separation between the $\mathrm{ZnO}$ film sample and the platinum plate of the photocell is $0.8 \mathrm{~mm}$.

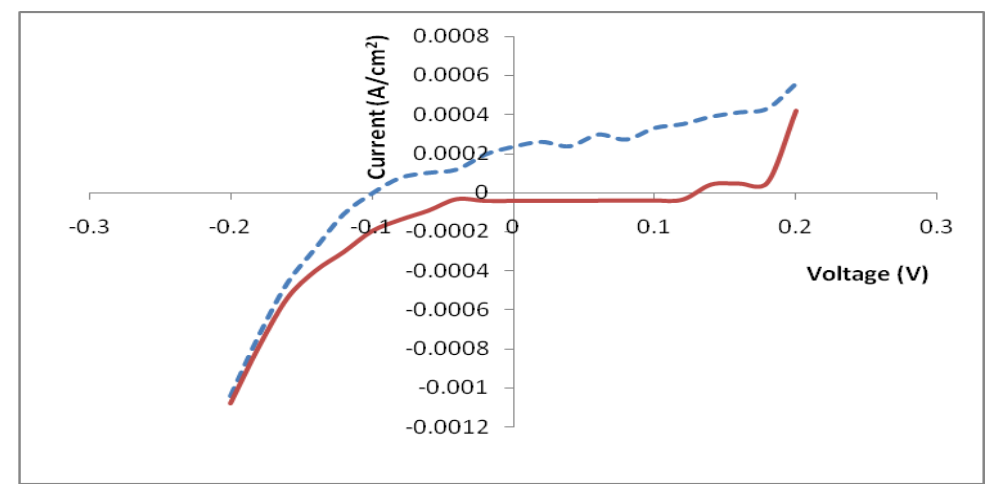

Figure 1: $\quad$ I-V curves of $\mathrm{ZnO}$ coated with methyl violet for 12 hours and electrodes of photocell separated by $0.8 \mathrm{~mm}$. Dashed line. Dark I-V curve ; solid line. Light I-V curve

The variation of efficiency with the separation between the $\mathrm{ZnO}$ film and the platinum plate of photocell is indicated in Figure 2. The power is defined as the product of 
voltage at $\mathrm{I}=0$ and current at $\mathrm{V}=0$, similar to the calculation given in previous paragraph. The dye coating time was kept at 12 hours for all these $\mathrm{ZnO}$ samples. The efficiency reaches optimum values when the separation between the $\mathrm{ZnO}$ film and platinum electrode is $0.8 \mathrm{~mm}$. Therefore, the efficiency becomes smaller at low and high values of separation. The efficiency versus dye coating time is shown in Figure 3. The separation between the $\mathrm{ZnO}$ film sample and the platinum electrode was kept at $0.8 \mathrm{~mm}$ in this case, in order to study only the effect of dye coating time. The dye was coated to enhance the light absorption, and the thickness of dye layer increases with dye coating time. The efficiency becomes small at less dye coating times because the film does not absorb enough light. On the other hand, the efficiency becomes small at high dye coating times, because the coated dye layer reduces the intensity of light reaching $\mathrm{ZnO}$ sample.

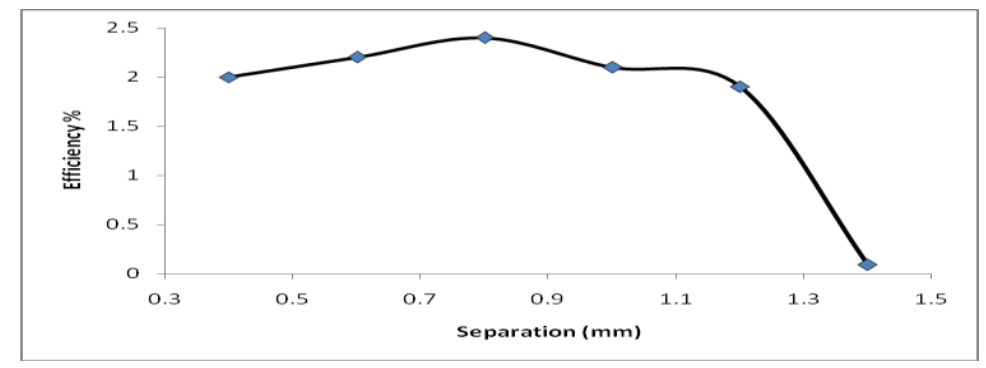

Figure 2: $\quad$ Efficiency of photocell versus the separation between the $\mathrm{ZnO}$ film and the platinum plate of photocell

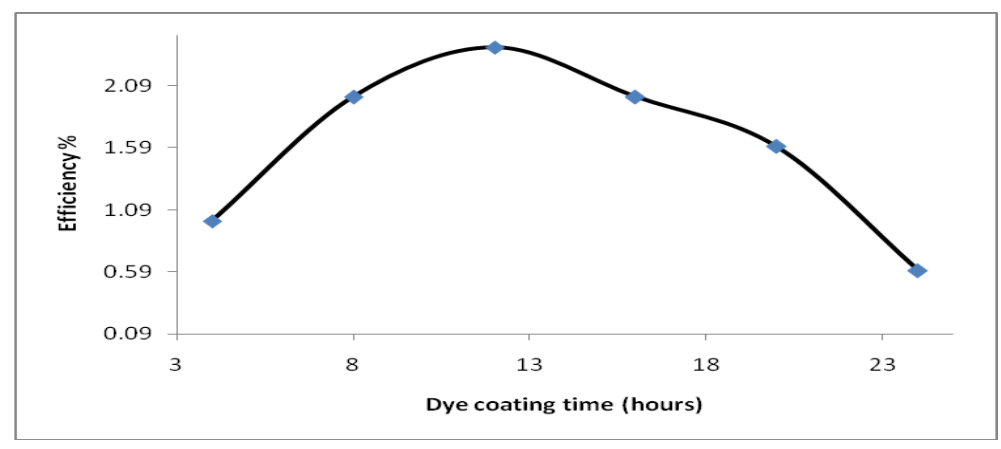

Figure 3: $\quad$ Efficiency of photocell versus methyl violet dye coating time

A part of $\mathrm{I}-\mathrm{V}$ characteristic curve of $\mathrm{ZnO}$ film coated with dye for 12 hours is given in Figure 4. The separation between the $\mathrm{ZnO}$ film and the platinum plate of this photocell is $1.4 \mathrm{~mm}$. The photocurrent at $\mathrm{V}=0$ is $\mathrm{I}=0.1 \mathrm{~mA} / \mathrm{cm}^{2}$, and the photo-voltage at $\mathrm{I}=0$ is $\mathrm{V}=$ $0.02 \mathrm{~V}$. Therefore, the effiency corresponding to this current and voltage is $0.09 \%$. This 
point is the last data point in Figure 2. This efficiency is much smaller than the efficiency at optimum conditions given in Figure 1. This indicates that the efficiency becomes smaller at higher separations between electrodes in photocell. Here again dashed and solid lines indicate the dark and light I-V curves, respectively.

The XRD pattern of a film sample is shown in Figure 5. According to this XRD pattern, a single phase of pure $\mathrm{ZnO}$ nanoparticles has been crystallized in the film sample.

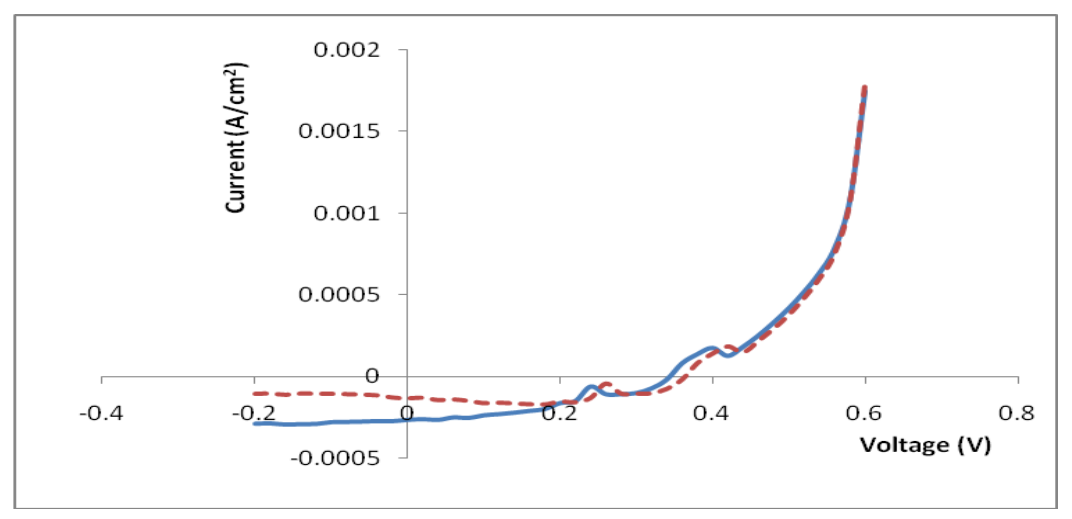

Figure 4: $\quad$ I-V curves of Zno coated with methyl violet for 12 hours and electrodes of photocell separated by $1.4 \mathrm{~mm}$. Dashed line. Dark I-V curve ; solid line. Light I-V curve

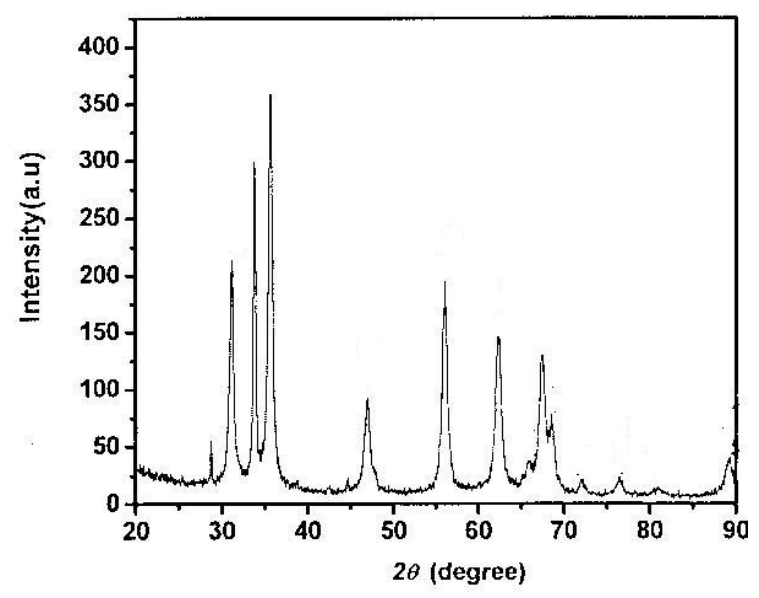

Figure 5: $\quad$ XRD pattern of a $\mathrm{ZnO}$ film sample before dye coating 


\section{CONCLUSIONS}

$\mathrm{ZnO}$ film samples prepared using a low cost method were employed to synthesize the liquid junction photocells filled with $\mathrm{KI} / \mathrm{I}_{2}$ solution described in this paper. The $\mathrm{ZnO}$ film samples were coated with methyl violet dye for 4-24 hours, and the separation between the $\mathrm{ZnO}$ sample and platinum electrode was varied in the range of 0.4 -1.4 mm, in order to study the effect of different conditions on the photovoltaic properties of $\mathrm{ZnO}$ liquid junction photocell. The optimum conditions could be obtained for 12 hours of dye coating and electrodes of photocell separated by $0.8 \mathrm{~mm}$. The optimum photocurrent, photo-voltage and efficiency were $0.24 \mathrm{~mA} / \mathrm{cm}^{2}, 0.22 \mathrm{~V}$ and $2.4 \%$, respectively. I-V characteristic curve of $\mathrm{ZnO}$ film coated with methyl violet dye for 12 hours and the photocell electrode separation of $1.4 \mathrm{~mm}$ indicates that the efficiency of the cell at other conditions is less than that at optimum conditions. Although it is possible to obtain a higher photo-voltage for $\mathrm{ZnO}$ films because of the higher band gap of $\mathrm{ZnO}$, it is difficult to obtain a higher photocurrent due to the same reason. Especially, the optimum photocurrent obtained by this low cost method is higher than that obtained by some other researchers using expensive methods.

\section{REFERENCES}

Bobrenko, Y.N., V.V. Kislyuk, K.V. Kolezhuk, V.N. Komashchenko, Pavelets \& T.E. Shengeliya. 1994. II-VI thin films polycrystalline multilayer converters for solar photovoltaics. Solar Energy Material \& Solar Cells 33: 83-90.

Cao, H., J.Y. Wu, H.C. Ong, J.Y. Dai \& R.P.H. Chang 1998. Second harmonic generation in laser ablated zinc oxide thin films. Applied Physsics Letters. 73(5): 572-574.

Jayaraj, M.K, A. Antony \& M. Ramachandran. 2002. Transparent conducting zinc oxide thin film prepared by off-axis rf magnetron sputtering. Bulletin of Material Science 25(3): 227-230.

Jeong S.H, S.B. Lee \& J.H. Boo. 2004. The insert of zinc oxide thin film in indium tin oxide anode for organic electroluminescence devices. Current Applied Physics 4: 655-658.

Jo, S.H., J.Y. Lao, Z.F. Ren, R.A. Farrer, T. Baldacchini \& J.T. Fourkas. 2003. Fieldemission studies on thin films of zinc oxide nanowires. Applied Physics Letters 83(23): 4821-4823. 
Knodler, R., J. Sopka, F. Harbach \& H.W. Grunling. 1993. Photoelectrochemical cells based on dye sensitized colloidal $\mathrm{TiO}_{2}$ layers. Solar Energy Materials \& Solar Cells. 30: 277-281.

Maruyama, T. \& S. Ari. 1993. The electrochromic properties of nickel oxide thin films prepared by chemical vapor deposition. Solar Energy Materials \& Solar Cells 30: 257-262.

Samarasekara, P., A.G.K. Nisantha \& A.S. Disanayake. 2002. High photo-voltage zinc oxide thin films deposited by dc sputtering. Chinese Journal Physics 40(2): 196-199. 
P Samarasekara 